\title{
The Impact of Triadic Strategic Alignment on Organisational Performance
}

\author{
Abdulrahman Al-Surmi ${ }^{1}$, Guangming $\mathrm{Cao}^{1}$, and Yanqing Duan ${ }^{1}$
}

\begin{abstract}
Strategic alignment is deemed crucial in understanding how organisational performance can be improved through supporting business strategy with other organisational strategies. Whilst previous alignment literature has provided foundations for identifying the dimensions and performance impacts of the strategic alignment, it is mainly based on dyadic relationships between, for example, business and information technology (IT), business and marketing, or IT and marketing, which could not include other vital variable to develop a more comprehensive understanding of strategic alignment and its impact on organisational performance. Based on a systematic literature review of prior research on strategic alignment, this research develops a research model of triadic strategic alignment of business, IT, and marketing strategies and its impact on organisational performance. It posits that the alignment will result in better organisational performance. Relevant hypotheses have been proposed, which should provide future research directions. Using data collected from 242 managers, and analysed with PLSSEM.
\end{abstract}

Keywords-Strategic alignment, IT strategy, Marketing strategy, Business performance

\section{INTRODUCTION}

$\mathrm{T}$ HE strategic alignment between business and IT strategy has attracted a great deal of scholarly interest [7, 24]. [30] defined alignment as "the degree to which the needs, demands, goals, objectives, and/or structures of one component are consistent with the needs, demands, goals, objectives, and/or structures of another component". Alignment is the concept at the heart of contingency theory, which is central to the development of the theory, to the collection of data, and to the statistical analysis of the proposition [15]. Contingency theorists have asserted a connection between strategic alignments and organisational performance, suggesting that organisational performance is a consequence of alignment between two or more factors.

Accordingly, much effort has been put on clarifying the relationship between business and IT strategies in the literature. The work of [35] and [25] spurred a substantial stream of research focusing on this construct's definition, measurement, backgrounds and consequences. The vast majority of the studies investigated strategic alignment influence on organisational performance. These studies examined the necessity and benefits of aligning IT with the rest of the business $[8,24]$.

Abdulrahman Al-Surmi ${ }^{1}$, Guangming $\mathrm{Cao}^{1}$, and Yanqing Duan ${ }^{1}$ are with ${ }^{1}$ University of Bedfordshire, University Square, Luton, LU1 3JU
Much of the work has examined the performance impact of aligning business and IT strategies [e.g. 6] and not much of researches on the impact of aligning marketing strategy with business strategy. However, the link between marketing strategy and IT strategy remains unclear and under-investigated: only a few articles have attempted to study the performance impact of marketing and IT alignment in the marketing literature [4, 21, 40].

There are also two methodological issues exist in the literature on strategic alignment. First, these studies have measured organisational performance through bivariate analysis, which leads to possible inconsistencies amongst multiple factors as many other factors can positively influence organisational performance. Second, the bivariate model is concentrated on measuring the alignment between two variables which has its limitations. Despite the sheer number of studies in strategic alignment field, research on the performance impact of strategic alignment has been primarily limited to considering only two strategic factors.

Thus, this research intends to fill the above research gaps by examining the performance impact of the strategic alignment among business, IT, and marketing strategies; seeking to develop a more holistic understanding of the impact of strategic alignment. It contributes to the current literature conceptually by developing a triadic strategic alignment model and empirically by testing this model.

The reminder of this paper is organised as follows. Section 2 provides a detailed literature review on the key types of organisational strategies and the two-way strategic alignment. Next, a research framework is developed to clearly describe the concept of triadic strategic alignment, together with, a set of specific hypotheses. The subsequent sections describe the instrument development and the data collection processes, and reports on the findings. The final section discusses the results and implications.

\section{LITERATURE REVIEW}

\section{A. Business strategy, IT strategy, and marketing strategy}

Business strategy is the general direction in which a firm chooses to move in order to achieve its goals and objectives, which is classified into prospector, defender, analyser, and reactor [28]. They are used for examining organisational strategies based on their degree of market aggressiveness. The key to success for prospector is the development of innovative new products and entry into new markets. For the defender, the key to success is focusing more narrowly on maintaining a secure position in existing product/market. As for the analyser, the key to success is maintaining stable domain of core products, whilst seeking new product/market opportunities. These typologies have been mainly used to assess both the strategy of an organisation and strategic alignment and have been subjected to extensive discussion 
and empirical investigation [37]. Unlike these three successful business strategies, reactor is considered a form of strategic 'failure' and has thus been excluded by most empirical studies $[35,47]$. Similarly, reactor will not be included in this research.

IT strategy is defined as how IT will be used to facilitate electronic communication to support business processes and needs $[5,20]$. It is a part of the overall business strategy although the focus is specifically on technology. Porter and Millar [34] discussed that IT strategy alters the rules and the structure of industries, thus allowing organisations to create competitive advantage. The importance of IT strategy to a firm is potentially increasing as IT has become a key element in competitive positioning [16].

IT strategies are classified into flexibility, efficiency, and comprehensiveness [35]. The flexibility IT strategy refers to use IT for observing marketing information and changes of market, and providing basis for decision making, which is seen to be consistent with firms adopting prospector strategy The efficiency IT strategy, which is ideally relevant to defender firms, refers to use IT for monitoring and controlling daily operations, facilitating operational efficiency, supporting function of information sharing and communication to link with customers and suppliers, and providing basis for decision making. The comprehensiveness IT strategy refers to employ IT for observing marketing information and market changes, supporting function of information sharing and communication to link with customers and suppliers, and providing basis for decision making. Also, this is the ideal IT strategy for analyser firms [28, 35].

In addition to business and IT strategies, the marketing strategy has been well researched to keep marketing strategically aligned with firm's strategic goals to achieve a better performance. Marketing strategy refers to the marketing activities and decisions related to generating and sustaining competitive advantage for the business [41]. Marketing activities are numerous and varied such as research and development, product design, promoting product, setting price, etc. These activities are very important in scanning environmental variables (customers and competitors). In other words, marketing strategy focuses on ways in which the firm can differentiate itself effectively from its competitors to deliver better value to its customers. Marketing strategies are often examined in terms of either customer or competitor [31, 42].

Based on [48], the strategic fit between strategy and environmental variables may be significant in determining the ultimate success of that strategy. [1] suggested that prospector tends to view the industry from its own internal perspective and its customer base rather than being concerned with the competition, while defender firms take their competitors seriously and cautiously as they attempt to react swiftly and with an intensive attack to any move by a competitor that it deems threatening. Somewhere in between these two more extreme forms of organisations are the analysers.

\section{B. Strategic orientation and strategic alignment}

Strategic orientation is a concept widely used in the research field of strategic management and strategic alignment literature. An organisation's strategic orientation reflects the strategic directions implemented by an organisation to create the proper behaviours for the continuous superior performance of the business [31]. The relationship between strategic orientation and organisational performance is influenced by third-party variables, and the different effects of third variables may lead to different performance levels [3]. Depending on the strategic orientation adopted, the organisation may emphasise more or less aspects such as technological position, innovation, organisational design and personnel management which determines performance levels [11].

Strategic IT alignment has remained amongst the top concerns of researchers for over two decades. Aligning IT strategy with business strategy is vitally important to improving organisational performance [7, 35]. Conversely, the lack of strategic alignment between business and IT strategies is believed to be risky and could possibly lead into a steady decline in competitive ability. Besides, [25] examined the linkage of both strategies asserting that the importance of strategic IT alignment is the key success factor for a successful firm. Also, [13] stressed to be attentive to various business areas such as business vision, strategy, and communication that remarked as great potential for improving the alignment of business and IT strategies. For the most part, aligning business and IT strategies proved to enhance firm's performance in the long term, yet there is a possibility of misalignment of which the degree varies from one organisation to another.

The strategic alignment between business strategy and marketing strategy is factor to increase an organisation's growth [48]. Marketing managers believe this alignment facilitates the achievement of business objectives and positively affects a firm's performance. On the other hand, [39] demonstrated that strategic misalignment leading to confusion amongst business and marketing managers could be caused by various reasons at different organisational levels. Still, research on the strategic alignment of business strategy and marketing strategy is limited.

The positive impact of IT and marketing alignment on business performance has been reported in the literature, for example, an internet-mediated marketing improving business performance [29]. IT strategic use can be assessed by the way firms utilise market information system (e.g. collecting customer and competitor information) to support its business strategy and marketing activities. In practical terms, alignment of these strategies ensures that IT provides marketing with the systems that marketing needs to accomplish its goals, or as [19] claimed that IT strategy supports marketing through the development of products and services. Therefore, IT strategy can enhance firm's performance better when it is aligned with marketing strategy.

\section{Research gaps and theoretical development}

The literature shows that prior studies mostly adopted the bivariate interaction model [15] to investigate the performance impact of alignment [7]. However, dyadic alignment is seriously limited as the bivariate model is concentrated on measuring the alignment between two variables ignoring the considerations of other crucial 
relationships. For example, [25] stated that marketing strategies might be potential antecedents to strategic alignment between business and IT and thus should not be excluded from strategic IT alignment. Alternatively, [19] stated dyadic alignment can lead to "possible inconsistencies amongst multiple forms of interrelated bivariate".

Unlike the bivariate, a multivariate relationship including multiple variables could give a richer and realistic view of strategic alignment [35] and greater explanatory power [45] because of its ability to retain the complex and interrelated nature of the relationships between constructs. Additionally, [44] argued that alignment is achievable amongst three or more factors. For example, [8] believed that aligning marketing strategies with business and IT strategies in a firm may enable it to achieve higher levels of alignment and better performance. [2] and [36] have empirically tested that multivariate relationships could create a competitive advantage. It is quite clear that multivariate relationships enable a firm to act as a whole in achieving the firm's goal.

Thus, this research follows [15] to emphasise the need to adopt a multivariate analysis to examine patterns of consistency amongst dimensions of organisational context, strategy, and performance. Specifically, this research develops a triadic alignment among business, IT, and marketing strategies to provide a richer view of strategic alignment and its performance impact (Fig. 1). To our knowledge, this has not been done by anyone.

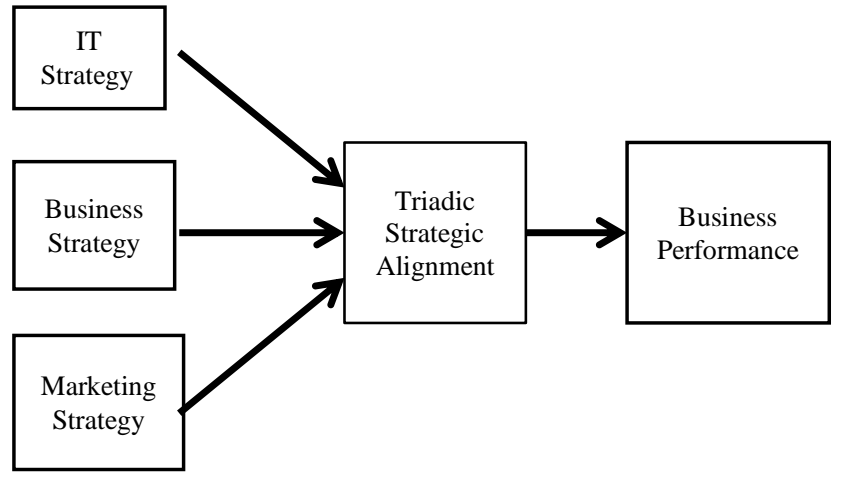

Fig. 1 The research model

\section{Hypotheses}

Thus, the key hypothesis of this research is:

H. The alignment between business strategy, IT strategy, and marketing strategy is positively associated with better firm performance.

Theoretical patterns of alignment depend on the constructs used to assess alignment domain [2]. The reviewed literature evidently proved that different business strategies require the support of different IT strategies and different marketing strategies.

Based on this, every business strategy has an ideal IT strategy and marketing strategy that can lead to better organisational performance. Since the prospector is continually innovating new products and entering new markets [28], it seeks flexibility in IT to respond quickly to changing market [35] in order to solve customer needs [38]. Then, this research expects prospector firms aligned ideally with IT flexibility strategy and customer-focused strategy will perform better than those prospector firms aligned with other IT or marketing strategy, which will be referred to as misalignment in this research.

Thus, poor performance could be the result of misalignment [32]. This will provide insight as to whether a firm that has achieved triadic strategic alignment would perform significantly better than a firm that has not. For example, alignment of IT flexibility strategy with prospector strategy is likely to work well than being aligned with defender strategy. This suggests the following:

H1. Prospector firm focused on customers aligned with IT flexibility strategy is more strongly associated with better performance than those prospector firms with other forms of alignment.

This research expects that defender firms are best aligned with the IT efficiency strategy and competitor-focused strategy. Otherwise, aligning defender firms with other IT and marketing strategies will cause misalignment. This suggests the following:

H2. Defender firm focused on competitor aligned with IT efficiency strategy is more strongly associated with better performance than those defender firms with other forms of alignment.

Likewise, analyser firm is a combination of the above two strategies. It maintains a stable domain of core products, whilst seeking new market opportunities [28]. [35] suggested that IT comprehensiveness strategy is better aligned with analyser firm as it enables comprehensive decisions and quick responses through knowledge of other organisations.

Also, analyser firm monitors customer reaction and competitors' activities [33]. Nonetheless, analyser firms can also be affected by misalignment if aligned with either IT flexibility or IT efficiency strategy. This suggests the following:

H3. Analyser firm focused equally on competitor and customer aligned with IT comprehensiveness strategy is more strongly associated with better performance than those analyser firms with other forms of alignment.

\section{RESEARCH METHOD}

\section{A. Sample and data collection}

To address the research hypotheses, a survey of private firms registered in the Ministry of Industry and Trade in Yemen from different industries has been conducted with IT, business, and marketing managers randomly selected from a sampling frame containing 1,201 firms. A pilot study has been conducted testing the questionnaire with minimum ten managers chosen from the list. The questionnaire was pretested and led to minor adjustments.

350 hard copy questionnaires were distributed to managers and executives in person on July 2014. One week later 187 were returned and a reminder was sent to the others. At the end of July a total of 257 questionnaires were collected for a response rate of $73 \%$. Table I summarises the profile of the respondents and their firms.

A data screening was performed which involved in the removal of unusable data to prevent the study from being biased. As a result, a total of 15 cases were excluded. 
TABLE I

RESPONDENT PROFILES (N=242)

\begin{tabular}{lc|lc}
\hline \hline \multicolumn{1}{c|}{ Firm Profile } & $(\%)$ & Respondent Profile & $(\%)$ \\
\hline \multicolumn{1}{c}{ Industry } & & Job Position & \\
Telecom & 29.8 & Business Manager & 12.0 \\
Banking & 25.2 & IT Manager & 6.2 \\
Manufacturing & 11.2 & Marketing Manager & 5.8 \\
Retail & 5.8 & Other Managers & 76.0 \\
Service & 4.1 & & \\
Property & 3.7 & & \\
Other & 20.2 & & \\
\hline \hline
\end{tabular}

\section{B. Measurements}

In order to measure the performance impact of triadic strategic alignment (TSA), 32 indicators have been adopted based on several studies. Likert 7-point scale ranging from "strongly disagree" to "strongly agree" was used to assess the level of alignment amongst business, IT, and marketing strategies.

Business strategy orientation (BSO) has been measured using nine indicators adapted from $[14,28]$ regarding a firm's proactiveness, defensiveness and analysis.

IT strategy orientation (ITSO) can be measured using nine indicators from $[14,35]$ to indicate IT strategy's flexibility, efficiency and comprehensiveness.

Marketing strategy orientation (MSO) can be measured using nine indicators adapted from [31, 33] to indicate whether a firm is customer-focused or competitor-focused [27].

Organisational performance $(O P)$ can be measured using five indicators adapted from $[12,25]$ to reflect the respondent's perception of a firm's sales growth, market share, and return on investment [43]

\section{RESULTS}

PLS was used to test the hypotheses using the dataset of 242. The analysis procedure involved testing the reflective measurement model, the formative measurement model and the structural model.

\section{A. Reflective measurement model}

Assessing reflective measurement model for the firstorder constructs and the criterion (performance) is determined by the quality of internal consistency (composite reliability), indicator reliability, convergent validity (average variance extracted (AVE)), and discriminant validity [17]. Based on [17, 23, 26], the above four indicators are assessed and summarised in Table II and III. The test results indicate that the reflective measurement model is satisfactory.

\section{B. Formative measurement model}

The estimates of second-order outer loadings and outer weights can be obtained along with structural relationships and their significance. According to [17], formative measurement is assessed by collinearity issues, and the significance and relevance of the formative indicators. Also, the formative measurement has to be investigated in terms of nomological validity to determine the quality of the measurement model [18]. Our results suggest that the formative measurement model is satisfactory.
TABLE II

CONVERGENT VALIDITY AND INTERNAL CONSISTENCY VALIDITY

\begin{tabular}{|c|c|c|c|c|c|c|}
\hline $\begin{array}{l}\text { Reflective } \\
\text { First-order } \\
\text { Constructs }\end{array}$ & M.I. & O.L. & I.R. & AVE & C.R. & $\alpha$ \\
\hline \multirow{3}{*}{ Proactiveness } & PRO1 & 0.71 & 0.50 & \multirow{3}{*}{0.51} & \multirow{3}{*}{0.75} & \multirow{3}{*}{0.51} \\
\hline & $\mathrm{PRO} 2$ & 0.72 & 0.51 & & & \\
\hline & PRO3 & 0.71 & 0.51 & & & \\
\hline \multirow{3}{*}{ Defensiveness } & DEF1 & 0.81 & 0.65 & \multirow{3}{*}{0.61} & \multirow{3}{*}{0.82} & \multirow{3}{*}{0.67} \\
\hline & DEF2 & 0.83 & 0.70 & & & \\
\hline & DEF3 & 0.69 & 0.48 & & & \\
\hline \multirow{3}{*}{ Analysis } & ANA1 & 0.81 & 0.65 & \multirow{3}{*}{0.69} & \multirow{3}{*}{0.87} & \multirow{3}{*}{0.78} \\
\hline & ANA2 & 0.84 & 0.71 & & & \\
\hline & ANA3 & 0.85 & 0.73 & & & \\
\hline \multirow{3}{*}{ Flexibility } & FLEX1 & 0.64 & 0.40 & \multirow{3}{*}{0.64} & \multirow{3}{*}{0.84} & \multirow{3}{*}{0.72} \\
\hline & FLEX2 & 0.86 & 0.74 & & & \\
\hline & FLEX3 & 0.88 & 0.77 & & & \\
\hline \multirow{3}{*}{ Efficiency } & EFF1 & 0.81 & 0.66 & \multirow{3}{*}{0.66} & \multirow{3}{*}{0.85} & \multirow{3}{*}{0.74} \\
\hline & EFF2 & 0.84 & 0.71 & & & \\
\hline & EFF3 & 0.77 & 0.60 & & & \\
\hline \multirow{3}{*}{$\begin{array}{c}\text { Comprehensive } \\
\text { ness }\end{array}$} & COMPR1 & 0.88 & 0.77 & \multirow{3}{*}{0.71} & \multirow{3}{*}{0.88} & \multirow{3}{*}{0.79} \\
\hline & COMPR2 & 0.88 & 0.78 & & & \\
\hline & COMPR3 & 0.76 & 0.58 & & & \\
\hline \multirow{5}{*}{$\begin{array}{l}\text { Customer- } \\
\text { focused }\end{array}$} & CUS1 & 0.76 & 0.58 & \multirow{5}{*}{0.57} & \multirow{5}{*}{0.87} & \multirow{5}{*}{0.81} \\
\hline & CUS2 & 0.80 & 0.64 & & & \\
\hline & CUS3 & 0.79 & 0.62 & & & \\
\hline & CUS4 & 0.63 & 0.40 & & & \\
\hline & CUS5 & 0.78 & 0.60 & & & \\
\hline \multirow{4}{*}{$\begin{array}{l}\text { Competitor- } \\
\text { focused }\end{array}$} & COMP1 & 0.78 & 0.61 & & & \\
\hline & COMP2 & 0.85 & 0.72 & 065 & 088 & 082 \\
\hline & COMP3 & 0.85 & 0.73 & 0.05 & 0.00 & 0.02 \\
\hline & COMP4 & 0.73 & 0.54 & & & \\
\hline & PERF1 & 0.83 & 0.70 & & & \\
\hline & PERF2 & 0.90 & 0.82 & & & \\
\hline Performance & PERF3 & 0.90 & 0.82 & 0.75 & 0.94 & 0.92 \\
\hline & PERF4 & 0.88 & 0.77 & & & \\
\hline & PERF5 & 0.81 & 0.66 & & & \\
\hline
\end{tabular}

M.I-Manifest Indicators, O.L-Outer Loadings, I.R-Indicator Reliability, C.R-Composite Reliability

TABLE III

INTER-CONSTRUCT CORRELATIONS

\begin{tabular}{|c|c|c|c|c|c|}
\hline Constructs & 1 & 2 & 3 & 4 & 5 \\
\hline $1 \mathrm{BSO}$ & $\mathrm{n} / \mathrm{a}$ & & & & \\
\hline 2 ITSO & 0.71 & $\mathrm{n} / \mathrm{a}$ & & & \\
\hline $3 \mathrm{MSO}$ & 0.67 & 0.73 & $\mathrm{n} / \mathrm{a}$ & & \\
\hline 4 PERF & 0.45 & 0.41 & 0.54 & 0.87 & \\
\hline 5 TSA & 0.85 & 0.91 & 0.91 & 0.53 & $\mathrm{n} / \mathrm{a}$ \\
\hline
\end{tabular}

Note: Diagonal elements are the square root of AVE and highlighted in bold; n/a-not applicable to formative constructs

\section{Structural model}

Estimating the structural model involves examining the model's predictive capabilities and the relationships between the constructs such as assessing collinearity issues, significance and relevance of the structural model relationships, the level of coefficient of determination $\left(R^{2}\right.$ value), and the predictive relevance $\left(Q^{2}\right.$ value) [17]. It is important before assessing the structural model to check for collinearity issues as it arises in the context of structural model evaluation when two constructs are highly correlated. The VIF values of the analyses are between 1.23 and 3.11 which are below the threshold 5 representing no collinearity issue in the structural model. 
The essential criterion for assessing the structural model is examining the $R^{2}$ values of the endogenous constructs [22]. The coefficient of determination is a measure of the proportion of an endogenous construct's variance that is explained by its predictor construct [17]. The $R^{2}$ value of performance construct is 0.28 which is slightly lower than moderate 0.33 [9]. Nonetheless, the performance construct has one exogenous dependent construct (i.e. TSA) with $R^{2}$ value 0 , therefore it is accepted. Looking at the path coefficient in Table IV, one finds that the triadic strategic alignment ultimately influences the key target construct, performance, via the formative constructs (BSO, ITSO, and MSO). The confidence intervals of the path coefficient was determined by setting the confidence intervals $90 \%$ (1.65), as recommended by Hair, Hult [17], then computed using the path coefficient value and standard error obtained from PLS. The total effect refers to the sum of the direct effect and all indirect effects linking two constructs.

TABLE IV

STRUCTURAL ESTIMATES.

\begin{tabular}{cccccc}
\hline \hline Path & $\begin{array}{c}\text { Total } \\
\text { Effect }\end{array}$ & $\beta$ & $\begin{array}{c}\text { Standard } \\
\text { error }\end{array}$ & $\rho$ value & $\begin{array}{c}90 \% \\
\text { Confidence } \\
\text { Interval }\end{array}$ \\
\hline BSO -> TSA & 0.56 & 0.28 & 0.02 & $0.0000^{* * * *}$ & $(0.25,0.31)$ \\
PRO -> BSO & 0.08 & 0.27 & 0.03 & $0.0000^{* * * *}$ & $(0.23,0.33)$ \\
DEF -> BSO & 0.15 & 0.45 & 0.03 & $0.0000^{* * * *}$ & $(0.41,0.50)$ \\
ANA -> BSO & 0.15 & 0.56 & 0.03 & $0.0000^{* * * *}$ & $(0.51,0.62)$ \\
ITSO -> TSA & 0.28 & 0.40 & 0.02 & $0.0000^{* * * *}$ & $(0.38,0.43)$ \\
FLEX -> ITSO & 0.51 & 0.34 & 0.02 & $0.0000^{* * * *}$ & $(0.32,0.38)$ \\
EFF -> ITSO & 0.12 & 0.42 & 0.02 & $0.0000^{* * * *}$ & $(0.39,0.46)$ \\
COMPR-> ITSO & 0.22 & 0.38 & 0.02 & $0.0000^{* * * *}$ & $(0.36,0.41)$ \\
MSO -> TSA & 0.57 & 0.43 & 0.02 & $0.0000^{* * * *}$ & $(0.41,0.47)$ \\
COMP -> MSO & 0.13 & 0.57 & 0.02 & $0.0000^{* * * *}$ & $(0.55,0.61)$ \\
CUS -> MSO & 0.25 & 0.51 & 0.02 & $0.0000^{* * * *}$ & $(0.49,0.55)$ \\
TSA -> PERF & 0.45 & 0.53 & 0.05 & $0.0000^{* * * *}$ & $(0.45,0.62)$ \\
\hline \hline
\end{tabular}

Next, we calculate the predictive relevance $\left(Q^{2}\right.$ value) which is critical to assess the predictive validity of a complex model [9]. Calculating the $\mathrm{Q}^{2}$ value is based on blindfolding procedure [17]. It shows how well the data collected empirically can be reconstructed with the help of model and the PLS parameters [46]. The $\mathrm{Q}^{2}$ values of BSO, ITSO, MSO, TSA, and performance endogenous constructs are $0.35,0.50,0.50,0.37$, and 0.20 respectively. The rule of thumb indicates that all $\mathrm{Q}^{2}$ values are above 0 [46]. Hence the observed values are well-reconstructed providing support for the model's predictive relevance

Thus the overall result indicates that the concept of triadic strategic alignment of business, IT, and marketing strategies with organisational performance is rather strong $(\mathbf{H}$. The alignment between business strategy, IT strategy, and marketing strategy is positively associated with better firm performance). We find a significant, positive impact of triadic strategic alignment on organisational performance (Table IV; TSA -> PERF $\beta=0.45, \mathrm{p}<0.001, R^{2}=0.28$ ).

Thereafter, we can compare forms of triadic strategic alignment based on the mean value of performance to clearly distinguish alignments level from one another. In order to compare the forms of triadic strategic alignment, we started classifying the level of alignment based on the business strategy typologies using the split file function in SPSS. The classification procedure is done by removing cases that did not score between 5 and 7 (somewhat agree, agree, and strongly agree) at PRO1, PRO2, and PRO3. This defines the firms that adopt prospector typology. Once the data has been classified the forms of triadic strategic alignment can, then, be categorised. For instance, prospector typology was categorised into three forms, namely, ideal alignment, medium alignment, and low alignment. Based on the reviewed literature, the ideal alignment for prospector firms is the relationship amongst prospector (business strategy), flexibility (IT strategy), and customer-focused (marketing strategy). Hence, we eliminated the cases that do not represent flexibility strategy and customer-focused strategy leaving 39 cases. Simultaneously, medium alignment for prospector firms is defined as having one ideal strategy, either flexibility strategy or customer-focused achieving 57 cases. Added to that, low alignment for prospector firms explains the adoption of neither flexibility strategy nor customer-focused strategy recording 3 cases in this study. The same procedure is applied for defender and analyser firms.

The means of the four performance components are presented in Table $\mathrm{V}$ excluding sales growth since its homogeneity is less than 0.05 . Table $\mathrm{V}$ reveals the ideal alignment level for each strategic orientation in every performance component is greater than medium and low except for low defender alignment, which is high compared to ideal and medium.

TABLE V

ALIGNMENT FORMS

\begin{tabular}{ccccccc}
\hline \hline $\begin{array}{c}\text { Business } \\
\text { Orientation }\end{array}$ & $\begin{array}{c}\text { Level of } \\
\text { Alignment }\end{array}$ & $\mathrm{n}$ & $\begin{array}{c}\text { Market } \\
\text { Share } \\
\text { Mean }\end{array}$ & $\begin{array}{c}\text { ROI } \\
\text { Mean }\end{array}$ & $\begin{array}{c}\text { Net } \\
\text { Profit } \\
\text { Mean }\end{array}$ & $\begin{array}{c}\text { F.L. } \\
\text { Mean }\end{array}$ \\
\hline \multirow{5}{*}{ Prospector } & Ideal & 39 & 5.64 & 5.64 & 5.41 & 5.49 \\
& Ledium & 57 & 4.60 & 4.47 & 4.40 & 4.49 \\
& F-ANOVA & & 11.39 & 14.04 & 12.30 & 11.00 \\
& Ideal & 64 & 5.91 & 5.61 & 5.52 & 5.66 \\
& Medium & 55 & 4.67 & 4.64 & 4.51 & 4.56 \\
Lefender & Low & 3 & 5.33 & 5.33 & 5.67 & 5.67 \\
& F-ANOVA & & 21.56 & 11.56 & 12.13 & 14.07 \\
& & $* * *$ & $* * *$ & $* * *$ & $* * *$ \\
\cline { 2 - 7 } & Ideal & 13 & 5.38 & 5.28 & 5.11 & 5.33 \\
& Medium & 73 & 4.47 & 4.74 & 4.62 & 4.67 \\
Analyser & Low & 9 & 3.56 & 3.89 & 3.44 & 4.11 \\
& F-ANOVA & & 13.58 & 9.31 & 9.72 & 9.49 \\
& & $* * *$ & $* * *$ & $* * *$ & $* * *$ \\
\hline \hline
\end{tabular}

$* * *: \mathrm{p}<.001$

\section{DISCUSSION AND CONCLUSION}

The main purpose of this research is to examine the role of triadic strategic alignment in the relation between business strategic orientation, IT strategic orientation, and marketing strategic orientation and business performance. Specifically, our study intends to uncover whether the association between the three strategic orientations have a significant effect on business performance. Our results have revealed a significant number of new results concerning the correlation between triadic strategic alignment and business performance.

\section{A. Conceptual implication}

One of the most important contributions of this study is the development of a definition of triadic strategic alignment that is robust enough to be applied to a wide variety of 
situations. The findings of the study have extended the existing research regarding strategic alignment [e.g. 2, 25, $33,35]$. Based on the theoretical context, this research proposed that the triadic strategic alignment should be defined as a third-order multidimensional formative construct. The second-order multidimensional formative constructs are appropriate when the objective is to assess triadic strategic alignment. When the objective is to confirm interrelationships of constructs, the proposed higher-order formative constructs are theoretically convincing structure.

Another important contribution of this study is that it empirically confirms that triadic strategic alignment enhances the relation between business, IT, and marketing strategies and business performance suggesting that firms with high degree of strategic orientation are more likely to influence performance positively. As theorised, all firstorder dimensions were found to be significant reflective indicators of the second-order constructs. In turn, business strategic orientation, IT strategic orientation, and marketing strategic orientation significantly influenced organisational performance.

Nevertheless, in this study, the low and medium alignments are considered as "misalignment" due to the fact that this research is focused on examining the hypotheses (Table VI) of the ideal strategic orientations in the triadic strategic alignment context. The overall findings reveal that perceived potentials of triadic strategic alignment have a significant impact on the perceived organisational performance. The findings contribute to the understanding of alternative strategic orientations showing that there is a significant presence of all different alignment levels of strategic orientation. It was possible to determine from the findings that organisational performance is better compared to the other combinations of strategic orientations of a firm. Although low alignment defender firms were found to have better performance in all performance components, this might have been found lower had the sample size been larger.

Furthermore the structural equation modelling is one of the well-known advanced methods utilised in strategic alignment literature. This research presents an empirical support for hypotheses 1, 2, and 3 lending further support to the antecedent's strategic alignment that triadic strategic alignment improves business performance.

TABLE VI

SUMMARY RESULTS OF HYPOTHESES TESTING

\begin{tabular}{|c|c|c|c|}
\hline & Hypothesised Path & Path Coefficient & $\begin{array}{l}\text { Empirical } \\
\text { evidence }\end{array}$ \\
\hline Hypothesis & TSA -> PERF & $0.45^{* * *}$ & Yes \\
\hline Hypothesis 1 & $\begin{array}{l}\text { Prospector with Ideal } \\
\text { alignments perform } \\
\text { better than } \\
\text { misalignment }\end{array}$ & $\begin{array}{l}\text { Larger mean value } \\
\text { in performance } \\
\text { components }\end{array}$ & Yes \\
\hline Hypothesis 2 & $\begin{array}{l}\text { Defender with Ideal } \\
\text { alignments perform } \\
\text { better than } \\
\text { misalignment }\end{array}$ & $\begin{array}{l}\text { Larger mean value } \\
\text { in performance } \\
\text { components }\end{array}$ & Yes \\
\hline Hypothesis 3 & $\begin{array}{l}\text { Analyser with Ideal } \\
\text { alignments perform } \\
\text { better than } \\
\text { misalignment }\end{array}$ & $\begin{array}{l}\text { Larger mean value } \\
\text { in performance } \\
\text { components }\end{array}$ & Yes \\
\hline
\end{tabular}

$* * *: \mathrm{p}<.001$

\section{B. Empirical implication}

In reconciling our research findings with previous theoretical and empirical work, potential implications can be drawn. There is now a substantial body of research that suggests that successful IT and marketing strategies implementation is required to adapt to business strategy for superior performance. Also it suggests that marketing strategy plays a crucial role in strategic alignment and is contingent on the specific strategy in use.

This research also has perspective implications for managers. Since our study differentiate between high performance and low performance firms throughout the level of alignment, managers can use the findings from our study to assist performance improvement. Results from this study indicate multiple levels of alignment impact differently on performance depending on the firm's business strategic orientation.

Moreover, this research has attempted to provide empirical illustration of the impact of triadic strategic alignment on organisational performance by using a higherorder multidimensional formative construct on multiple measures of performance. It becomes evident that researchers need to be aware of the conceptual differences between reflective and formative measurement model approaches. The analysis of formative constructs in PLSSEM is an easy task and it is more suitable in handling hierarchical model.

\section{Limitations}

Despite the above contributions, there are two limitations of the study that suggested caution in interpreting and applying research findings. First, this study suffers from the issue of a small sample size. It has utilised a participation of 242 managers, which is relatively limited. Although the sample represents a wide range of industries, they are mainly from the telecom and banking sector. As indicated by Chung [10], a larger sample size can minimise the opportunity for biased results and improve the generalisation of the results established.

Secondly, the new model should be tested in different contexts to establish external validity. It is currently not known how well this research's higher-order model and its findings will generalise beyond the specified conditions in this research such as utilising PLS path modelling which cannot use the formal testing procedures allowing for the assessment of the validity of global model fit [49].

\section{Future research}

Despite the preceding limitations, this study theoretically and empirically links three strategies to triadic strategic alignment and business performance. The research model describes the relation between three strategies that are hypothesised to create triadic strategic alignment that facilitate business performance. Results show strong associations between the triadic strategic alignment and business performance. However, future research is encouraged to investigate the generalisability of the proposed second-order multidimensional formative constructs in other settings. Another interesting route for future research is considering the moderating role of other facilitators' i.e. organisational structure or environmental 
dynamisms would have been able to give more understanding to the relationship. The triadic strategic alignment constitutes a valid theoretical foundation on which to further investigate the fundamental strategic orientations of organisations.

Given the relatively low $R^{2}$ value measure for performance, future research may consider additional constructs such as organisational structure or environmental dynamisms. It would be also useful to utilise different path modelling such as CB-SEM, and to compare performance under a number of different conditions such as sample size, hierarchal model complexity, number of indicators per construct, etc.

\section{REFERENCES}

[1] Bamford, C.E. and West, G.P. Strategic Management: Value Creation, Sustainability, and Performance. South-Western Cengage Learning, 2010.

[2] Bergeron, F., Raymond, L., and Rivard, S. Ideal patterns of strategic alignment and business performance. Information \& Management, 41, 8 (2004), 1003-1020.

http://dx.doi.org/10.1016/j.im.2003.10.004

[3] Bing, L. Relationship between Strategic Orientation and Organizational Performance in Born Global: A Critical Review. International Journal of Business and Management, 6, 3 (2011),

[4] Blotnicky, K., Examining the Impact of Marketing Orientation on Information Technology Adoption in Canadian Firms. 2009, Northcentral University: USA. AAT.

[5] Broadbent, M. and Weill, P. Improving business and information strategy alignment: Learning from the banking industry. IBM Systems Journal, 32, 1 (1993), 162-179. http://dx.doi.org/10.1147/sj.321.0162

[6] Camillus, J.C. and Lederer, A.L. Corporate Strategy and the Design of Computerized Information Systems. Sloan Management Review, 26, 3 (1985), 35-42.

[7] Chan, Y.E., Huff, S.L., Barclay, D.W., and Copeland, D.G. Business Strategic Orientation, Information Systems Strategic Orientation, and Strategic Alignment. Information Systems Research, 8, 2 (1997), 125 150. http://dx.doi.org/10.1287/isre.8.2.125

[8] Chen, L. Business-IT alignment maturity of companies in China Information \& Management, 47, 1 (2010), 9-16. http://dx.doi.org/10.1016/j.im.2009.09.003

[9] Chin, W.W., Marcolin, B.L., and Newsted, P.R. A Partial Least Squares Latent Variable Modeling Approach for Measuring Interaction Effects: Results from a Monte Carlo Simulation Study and an Electronic-Mail Emotion/Adoption Study. Information Systems Research, 14, 2 (1998), 189-217. http://dx.doi.org/10.1287/isre.14.2.189.16018

[10] Chung, H.F.L. Market orientation, guanxi, and business performance. Industrial Marketing Management, 40, 4 (2011), 522-533. http://dx.doi.org/10.1016/j.indmarman.2010.12.008

[11] Conant, J.S., Mokwa, M.P., and Varadarajan, P.R. STRATEGIC TYPES, DISTINCTIVE MARKETING COMPETENCIES AND ORGANIZATIONAL PERFORMANCE: A MULTIPLE MEASURES-BASED STUDY. Strategic Management Journal, 11, 5 (1990), 365-383 http://dx.doi.org/10.1002/smj.4250110504

[12] Croteau, A.-M. and Bergeron, F. An information technology trilogy: business strategy, technological deployment and organizational performance. The Journal of Strategic Information Systems, 10, 2 (2001), 77-99. http://dx.doi.org/10.1016/S0963-8687(01)00044-0

[13] De Haes, S. and Van Grembergen, W. An Exploratory Study into IT Governance Implementations and its Impact on Business/IT Alignment. Information Systems Management, 26, 2 (2009), 123-137. http://dx.doi.org/10.1080/10580530902794786

[14] Dong, X., Liu, Q., and Yin, D. Business Performance, Business Strategy, and Information System Strategic Alignment: An Empirical Study on Chinese Firms. Tsinghua Science \& Technology, 13, 3 (2008), 348-354 http://dx.doi.org/10.1016/S1007-0214(08)70056-7

[15] Drazin, R. and Van de Ven, A.H. Alternative Forms of Fit in Contingency Theory. Administrative Science Quarterly, 30, 4 (1985), 514-539. http://dx.doi.org/10.2307/2392695

[16] Gartlan, J. and Shanks, G. THE ALIGNMENT OF BUSINESS AND INFORMATION TECHNOLOGY STRATEGY IN AUSTRALIA Australasian Journal of Information Systems, 14, 2 (2007), 113-139. http://dx.doi.org/10.3127/ajis.v14i2.184

[17] Hair, J.F., Hult, G.T.M., Ringle, C., and Sarstedt, M. A Primer on Partial Least Squares Structural Equation Modeling (PLS-SEM). SAGE Publications, 2013.

[18] Hardin, A.M., Chang, J.C.-J., and Fuller, M.A. Formative vs. Reflective Measurement: Comment on Marakas, Johnson, and Clay (2007). Journal of the Association for Information Systems, 9, 9 (2008), 519-534.

[19] Henderson, J.C. and Venkatraman, N. Strategic alignment : a framework for strategic information technology management. Cambridge, Mass. : Center for Information Systems Research, Sloan School of Management, Massachusetts Institute of Technology, 1989.

[20] Henderson, J.C. and Venkatraman, N. Strategic alignment: leveraging information technology for transforming organizations. IBM Syst. J., 32, 1 (1993), 4-16. http://dx.doi.org/10.1147/sj.382.0472

[21] Jaworski, B.J. and Kohli, A.K. Market orientation: Antecedents and consequences. Journal of Marketing, 57, 3 (1993), 53

[22] Jörg, H., Christian, M.R., and Rudolf, R.S., The use of partial least squares path modeling in international marketing, in New Challenges to International Marketing. 2009. p. 277-319.

[23] Kapoor, K., Dwivedi, Y.K., Piercy, N., and Lal, B. RFID Integrated Systems in Libraries: Extending TAM Model for Empirically Examining the Use. Journal of Enterprise Information Management, 27, 6 (2014), 1-23. http://dx.doi.org/10.1108/JEIM-10-2013-0079

[24] Kearns, G.S. and Lederer, A.L. A Resource-Based View of Strategic IT Alignment: How Knowledge Sharing Creates Competitive Advantage. Decision Sciences, 34, 1 (2003), 1-29. http://dx.doi.org/10.1111/1540-5915.02289

[25] Kearns, G.S. and Sabherwal, R. Strategic Alignment Between Business and Information Technology: A Knowledge-Based View of Behaviors, Outcome, and Consequences. Journal of Management Information Systems, 23, 3 (2006), 129-162. http://dx.doi.org/10.2753/MIS0742-1222230306

[26] Kundu, G.K. and Bairi, J. A scale for measuring the applicability of lean practices in IT support services. Journal of Enterprise Information Management, 27, 5 (2014), 1-25. http://dx.doi.org/10.1108/jeim-02-2013-0005

[27] McDaniel, S.W. and Kolari, J.W. Marketing Strategy Implications of the Miles and Snow Strategic Typology. Journal of Marketing, 51, 4 (1987), 19-30. http://dx.doi.org/10.2307/1251245

[28] Miles, R.E., Snow, C.C., Meyer, A.D., and Coleman, J.H.J. Organizational Strategy, Structure, and Process. Academy of Management Review, 3, 3 (1978), 546-562. http://dx.doi.org/10.5465/AMR.1978.4305755

[29] Min, S., Song, S., and Keebler, J.S. AN INTERNET-MEDIATED MARKET ORIENTATION (IMO): BUILDING A THEORY. Journal of Marketing Theory \& Practice, 10, 2 (2002), 1.

[30] Nadler, D.A. and Tushman, M.L. A Model for Diagnosing Organizational Behavior. Organizational Dynamics, 9, 2 (1980), 3551. http://dx.doi.org/10.1016/0090-2616(80)90039-X

[31] Narver, J.C. and Slater, S.F. The effect of a market orientation on business profitability. Journal of Marketing, 54, 4 (1990), 20-35. http://dx.doi.org/10.2307/1251757

[32] Obel, B., Burton, R., and Lauridsen, J. Fit and Misfits in the MultiDimensional Contingency Model: An Organizational Change Perspective. Research Center for Management, Organization, and Competence, (2000)

[33] Olson, E.M., Slater, S.F., and Hult, G.T.M. The Performance Implications of Fit Among Business Strategy, Marketing Organization Structure, and Strategic Behavior. Journal of Marketing, 69, 3 (2005), 49-65. http://dx.doi.org/10.1509/jmkg.69.3.49.66362

[34] Porter, M.E. and Millar, V.E. How information gives you competitive advantage. Harvard Business Review, 63, 4 (1985), 149-160.

[35] Sabherwal, R. and Chan, Y.E. Alignment Between Business and IS Strategies: A Study of Prospectors, Analyzers, and Defenders. Information Systems Research, 12, 1 (2001), 11.

[36] Schniederjans, M. and Cao, Q. Alignment of operations strategy, information strategic orientation, and performance: an empirical study. International Journal of Production Research, 47, 10 (2009), 25352563.

http://dx.doi.org/10.1080/00207540701673465 
[37] Segev, E. A Systematic Comparative Analysis and Synthesis of Two Business-Level Strategic Typologies. Strategic Management Journal, 10, 5 (1989), 487-505.

http://dx.doi.org/10.1002/smj.4250100507

[38] Slater, S.F., Hult, G.T.M., and Olson, E.M. Factors influencing the relative importance of marketing strategy creativity and marketing strategy implementation effectiveness. Industrial Marketing Management, 39, 4 (2010), 551-559. http://dx.doi.org/10.1016/j.indmarman.2008.03.007

[39] Strahle, W.M., Spiro, R.L., and Acito, F. Marketing and Sales: Strategic Alignment and Functional Implementation. Journal of Personal Selling \& Sales Management, 16, 1 (1996), 1-20.

[40] Talvinen, J.M. Information systems in marketing. European Journal of Marketing, 29, 1 (1995), 8-26. http://dx.doi.org/10.1108/03090569510075307

[41] Varadarajan, P.R., Jayachandran, S., and White, J.C. Strategic Interdependence in Organizations: Deconglomeration and Marketing Strategy. Journal of Marketing, 65, 1 (2001), 15-28. http://dx.doi.org/10.1509/jmkg.65.1.15.18129

[42] Varadarajan, R. Strategic marketing and marketing strategy: domain, definition, fundamental issues and foundational premises. Journal of the Academy of Marketing Science, 38, 2 (2010), 119-140. http://dx.doi.org/10.1007/s11747-009-0176-7

[43] Venkatraman, N. Strategic orientation of business enterprises: the construct, dimensionality, and measurement. Management Science, 35, 8 (1989), 942-962. http://dx.doi.org/10.1287/mnsc.35.8.942

[44] Venkatraman, N. and Camillus, J.C. Exploring the Concept of "Fit" in Strategic Management. Academy of Management Review, 9, 3 (1984), 513-525. http://dx.doi.org/10.5465/AMR.1984.4279696

[45] Venkatraman, N. and Prescott, J.E. Environment-strategy coalignment: An empirical test of its performance implications. Strategic Management Journal, 11, 1 (1990), 1-23. http://dx.doi.org/10.1002/smj.4250110102

[46] Vinzi, V.E., Chin, W.W., Henseler, J., and Wang, H. Handbook of Partial Least Squares: Concepts, Methods and Applications. Springer, 2010. http://dx.doi.org/10.1007/978-3-540-32827-8

[47] Vorhies, D.W. and Morgan, N.A. A Configuration Theory Assessment of Marketing Organization Fit with Business Strategy and Its Relationship with Marketing Performance. Journal of Marketing, 67, 1 (2003), 100-115. http://dx.doi.org/10.1509/jmkg.67.1.100.18588

[48] Walker Jr, O.C. and Ruekert, R.W. Marketing's Role in the Implementation of Business Strategies: A Critical Review and Conceptual Framework. Journal of Marketing, 51, 3 (1987), 15-33. http://dx.doi.org/10.2307/1251645

[49] Wetzels, M., Odekerken-Schröder, G., and van Oppen, C. Using PLS path modeling for assessing hierarchical construct models: guidelines and empirical illustration. MIS Quarterly, 33, 1 (2009), 177-195. 